Jonathon Crewe I University of West London, UK

\title{
WRITING AS A RESEARCH METHODOLOGY
}

An Argument in Support of Practice-Led Research

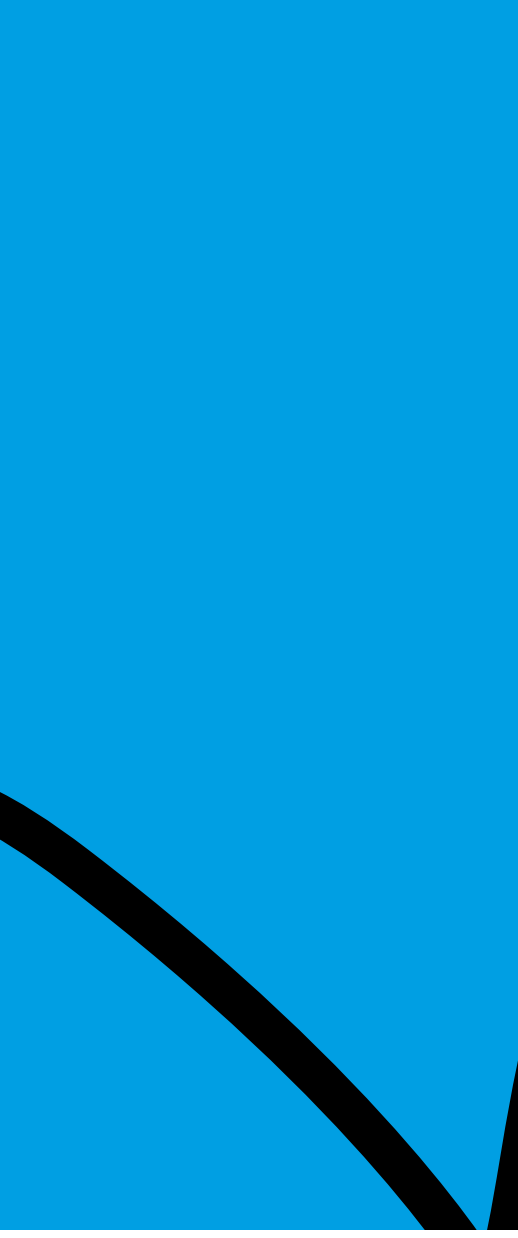




\section{One strength of practice- led research is the potential to bridge the gap between academia and the general public. The UK Research Excellence Framework's definition of impact beyond academia is 'an effect on, change or benefit to...an audience, community, constituency, organisation or individuals'}

W ithin Arts and Humanities departments across academia, it is not unusual to find researchers who split their time between more 'traditional' research methodologies and their own professional and creative practice. Indeed, I am one of them. As well as being a Senior Lecturer and researcher producing papers such as this, I am also a creative writer working across film and theatre. Having insights into the production of both forms of outputs, it is clear that there are many similarities in their aims and methods. Combining these into a practice-led research approach, allowing synergies and dialogue to develop, offers the opportunity for deriving unique insights that may otherwise have been overlooked. This article argues that creative writing, in all its various forms, is a valuable research methodology - an argument that could be extended to all practice-led research disciplines.

One strength of practice-led research is the potential to bridge the gap between academia and the general public. The UK Research Excellence Framework's definition of impact beyond academia is 'an effect on, change or benefit to...an audience, community, constituency, organisation or individuals' (REF, 2018, p.83). Whereas social scientists may work with and theorise about group or community identities, individuals do not experience these groups per se, rather they experience interactions with other individuals who may be members of a group. Creative writing, as a practice-based research approach, provides a route to resolving this dilemma by accessing group and community identities from the perspectives of individuals within a particular group or those who have interactions with individuals from this group. Fiction facilitates the portrayal of, and access to, complex and nuanced interiorities (inner character) through the lived experiences of relatable characters, presenting

'people and situations in their contexts with multidimensionality...as a method of disrupting dominant ideologies or stereotypes by...[describing] social reality and then [presenting] alternatives to that reality. One of the main advantages of fiction as a research practice is the...[ability] to promote empathy, build bridges of understanding across differences, and stimulate self-reflection' (Leavy, 2014, p.298).
Practice-led research can produce externalisations of interior knowledge and understanding, as well as exposing socio-cultural frameworks for contextual critical analysis and reflection. Creative writing works to explore the 'human process of making meaning through experiences that are felt, lived, reconstructed and reinterpreted,' and this includes both the writing and the reading process, where 'meanings are "made" from the transactions and narratives that emerge and these have the power and agency to change on an individual or community level' (Sullivan, 2009, p.50).

Creative writing allows the researcher access to the individual, but also to go beyond the personal, whereby the "methods and theoretical ideas as paradigms may be viewed as the apparatuses, or procedures of production from which the research design emerges' (Barrett, 2010, p.138, original italics). Although creative writing provides the researcher and reader with unique insights, it cannot fully realise its research potential without a framework for theoretical and contextual analysis and reflection. A practicebased researcher must maintain a discourse between the artefact and the exegesis, in order to exploit findings and outcomes so that a wider impact can be realised. As such, the creative writing process works in dialogue with continued critical and contextual analysis. In The Political Unconscious, Frederic Jameson argues that 'the production of aesthetic or narrative form is to be seen as an ideological act in its own right' (Jameson, 2010, p.64). Therefore, the process of creative writing can be analysed in terms of it being a socially symbolic act, whereby the inclusion and usage of ideologemes can be exposed and interrogated. In this context, an ideologeme is understood, according to Jameson, as both a conceptual construction and narrative sign, incorporating concepts such as beliefs and opinions as well as minimal units of socially symbolic narrative acts. As such, they can be seen as the inherited units of representation upon which the process of writing and rewriting through interpretation bases its narrative construction. As Jameson puts it, by their respective positions in the whole complex sequence of the modes of production, both the individual text and its ideologemes... must be read in terms of... 


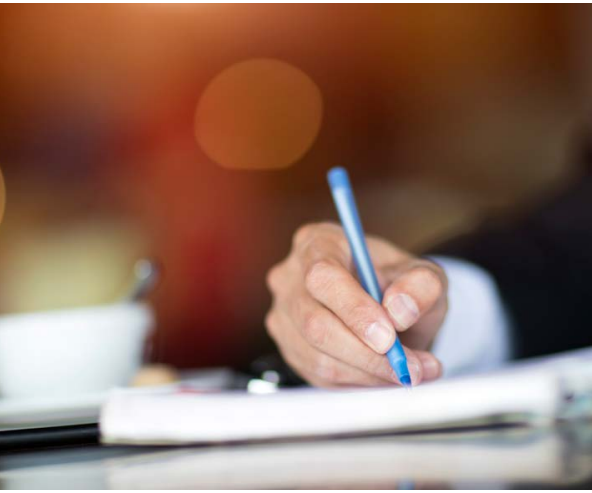

the ideology of form, that is, the symbolic messages transmitted... by the coexistence of various sign systems which are

themselves traces or anticipations of modes of production' (Jameson, 2010, p.61).

As such, narrative texts are not individual entities, but exist within the wider body of the literary canon, reflecting the social order in which they were written. In addition, practice-based researchers, similar to more traditional researchers, inevitably develop their methods and techniques in relation to the existent and recognised practices of their predecessors and contemporaries (Barrett, 2010). An understanding of this suggests a duality for the creative writing researcher, whereby a 'double movement occurs, of decontextualisation in which the found elements are rendered strange, and of recontextualisation, in which new families of association and structures of meaning are established' (Carter, 2010, pp.15).

This process not only informs the creative writing researcher, but also the reader of the text. For an example of how this works, this article will consider a creative writing research project in the form of a novel that aims to investigate a particular marginalised social group, whilst challenging typified representations of that group in mainstream media and politics (for a practice-led research project that does this, see Crewe, 2017). In line with the UK Research Excellence Framework's definition above, a novel can create a change in the behaviour and attitudes of its readers, as well as bringing potential benefits to a community - with respect to this example, a particular marginalised group.

Monica Ali and Caryl Phillips are both contemporary authors who have written from the perspective of individual characters from groups often vilified by mainstream media-for example, the Bangladeshi immigrant Nazneem in Ali's Brick Lane (2007), or the African asylum seeker Gabriel / Solomon in Phillip's A Distant Shore (2004). By providing extended, vivid and nuanced insights into the minds of individuals from groups often portrayed with homogenised negative stereotypes in mainstream media, Ali and Phillips work to challenge these tropes, individuate their characters and elicit sympathy from the reader (see Booth, 1983). In other words, the individualisation of a marginalised voice moves the character beyond the sociological and into the psychological, the point where representational

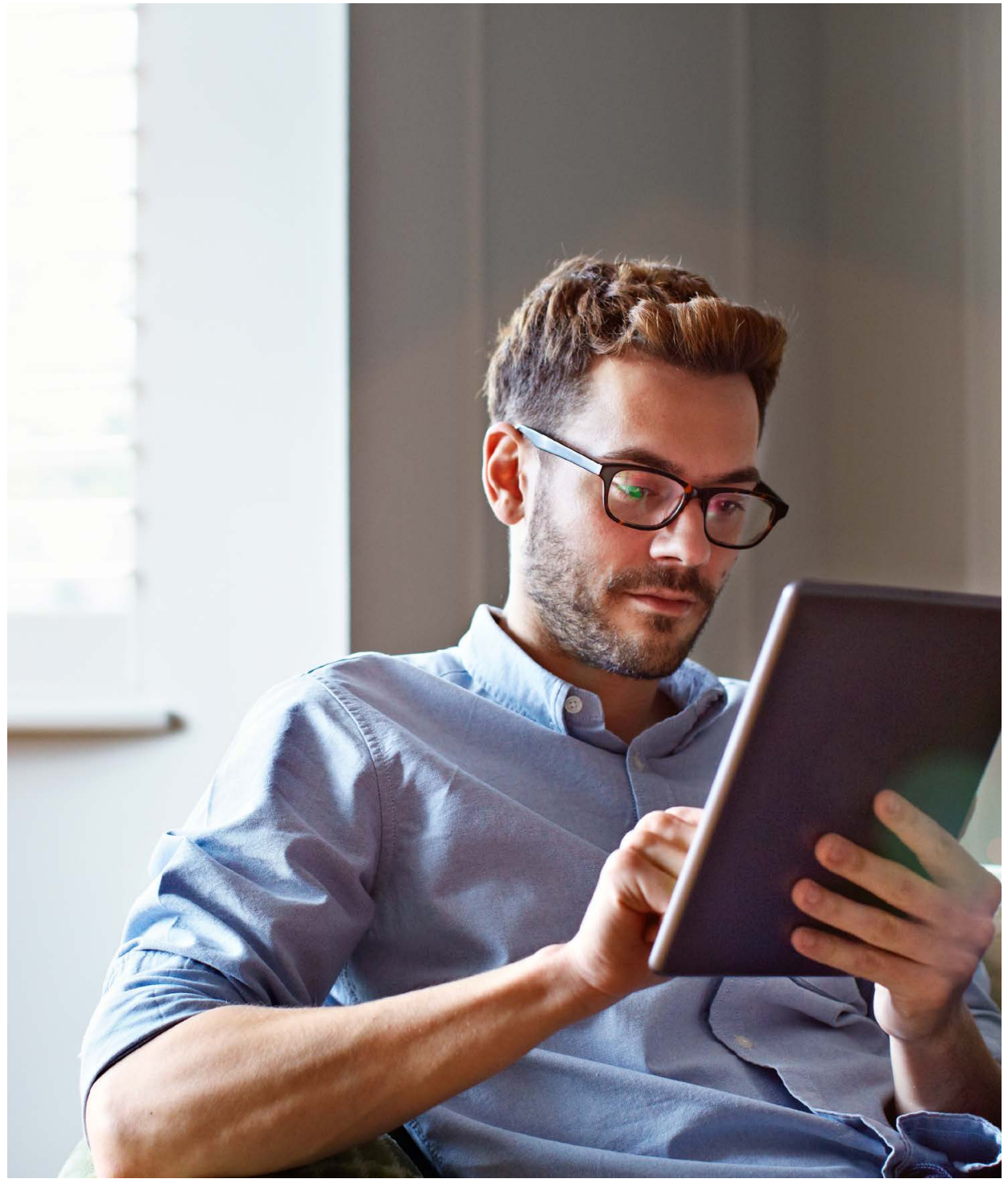

A novel can create a change in the behaviour and attitudes of its readers, as well as bringing potential benefits to a community, such as, for example, a particular marginalised group 


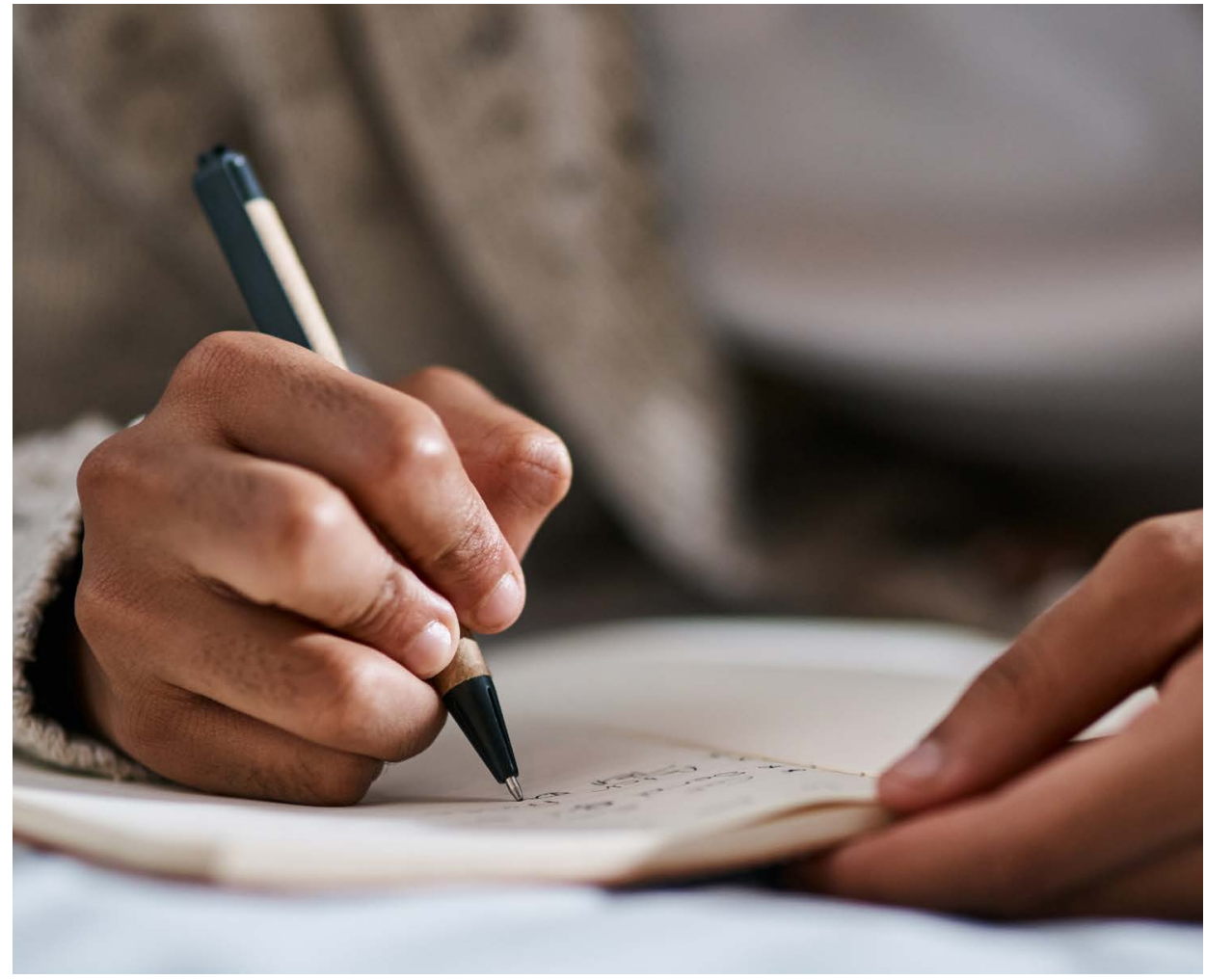

At times, readers of literary texts find themselves participating in an unconventional flow of feelings through which they realize something that they have not previously experiencedor at least...not...in the form provided by the text

meaning can occur in narrative form, in the sense that 'the psychological impulse tends toward the presentation of highly individualised figures who resist abstraction and generalisation, and whose motivation is not susceptible to rigid ethical interpretation' (Scholes, Phelan \& Kellogg, 2006, p. 101; see also Currie, 2010 and Jameson, 2010). In the above example, the creative writing researcher's conscious attempt to shift perceptions from a typified reading of characters from a marginalised group to a de-homogenised, individuated reading, serves to exploit Jameson's concept of rewriting texts through the interpretation process, whereby any given literary text cannot be viewed as independent and autonomous in itself, but rather as being 'rewritten' as part of a set of traditional interpretative functions during the process of reading. The reader's 'real-life' assumptions about the lifestyles and behaviour of these groups are exposed and challenged through their own interpretation of the characters' lifestyles, behaviour and choices within the 'fictional world' of the text.
Howard Sklar (2013) claims that emotions, in particular sympathy and compassion, felt by a reader in response to a fictional character can have 'ethical implications beyond the experience of reading itself... [Although] directed towards imaginary individuals, they may lay a foundation for emotional and ethical sensitivity in real life' (p.9; see also Kuiken, Miall \& Sikora, 2004). This process allows the reader to recognise the emotional and psychological experience of a character, providing a route to the identification and re-evaluation of pre-existing assumptions about a person or character from a particular excluded or 'other' group. Although readers will possess existing 'interpretive frames and experiences to the reading of a given text, the narrative itself provides its own counterweight to personal presumptions by "persuading" readers to feel and to evaluate characters in particular ways' (Sklar, 2013, p.59). This re-framing of the reader's interpretive perspective will not only involve a re-evaluation of a character's behaviour and lifestyle choices, but also of the reader's systems of belief in relation to the

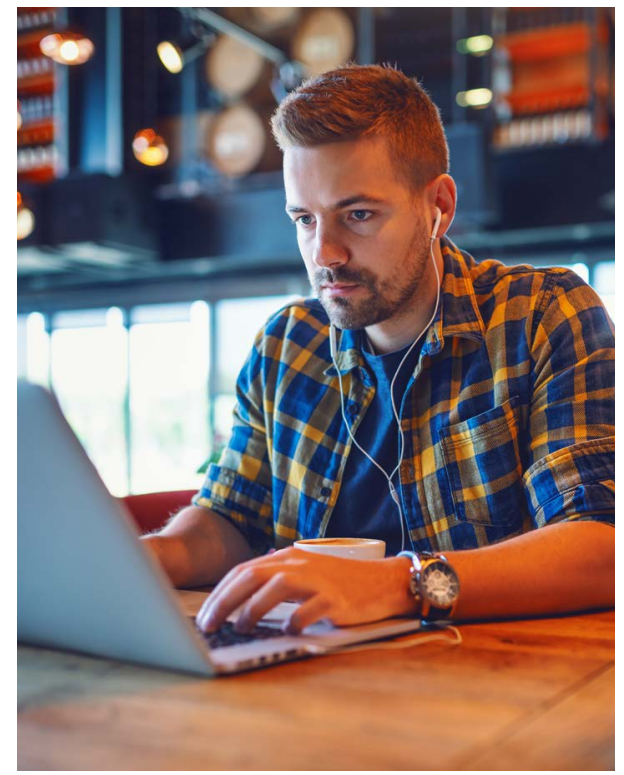

character's social group. As with Booth and Sklar, Currie (2010) argues that 'sustained imaginative engagement with a vividly expressed and highly individuated mental economy through a long and detailed narrative can ... be expected to have... finely-tuned imitative consequences, with correspondingly powerful results in terms of framing' (p.104). Narratologists have regularly pointed to focalisation, that is, 'seeing' from a character's perspective, as a technique for achieving this re-framing effect, inducing readers to view the narrative from a perspective that is not their own. For example, Sklar (2013) suggests that this re-framing effect is similar to the process of defamiliarisation, where readers are forced to reassess their 'familiar' assumptions about the fictional/real world as a result of shifts in perspective of the narrative's subject of focalisation, which 'may challenge readers to re-construct their representations of that character's feelings or attitudes' (p.69). Kuiken, Miall and Sikora (2004) discuss a set of phenomenological studies they undertook to investigate how defamiliarisation can lead to what they call 'self-modifying feelings' in the readers of literary texts:

'At times, readers of literary texts find themselves participating in an unconventional flow of feelings through which they realize something that they have not previously experienced - or at least. not...in the form provided by the text...The imagined world of the text can become unsettling. What is realized (recognized) also may become realized (made real) and carried forward as a changed understanding of the reader's own life-world' (Kuiken, Miall \& Sikora, 2004, pp.268). 


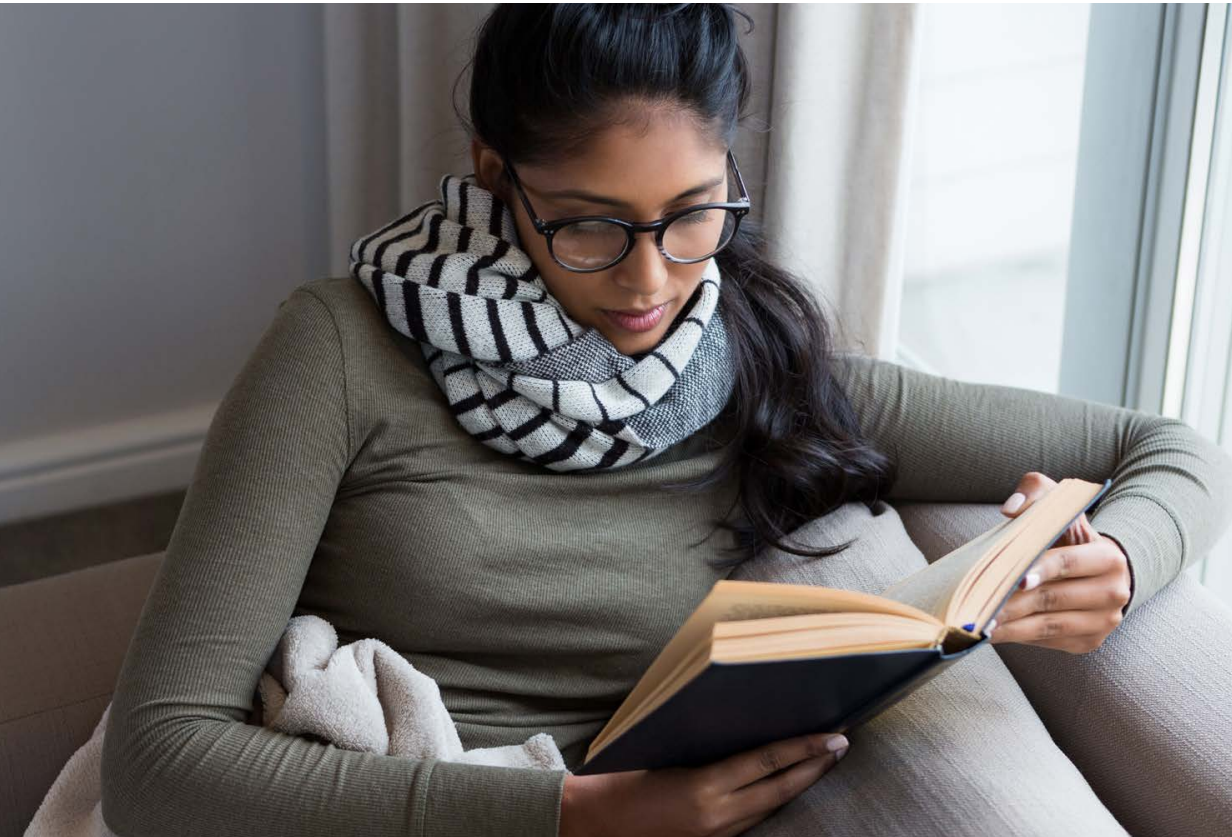

Identification with an individuated character can elicit emotions of sympathy and compassion from the reader, forcing them to re-evaluate their judgements of the character within the fictionalised world - one of the key strengths of practice-based research (Leavy, 2014). Creative writing takes us 'to where we've never been, to see what we've never seen...[then brings] us back... [to] look again at what we thought we knew' (Sullivan, 2010, p.62). These self-modifying feelings can instigate changes in the reader's attitudes to parallel/comparable real-life situations.

Creative writing can exploit the nature of realist fiction by portraying aspects of a world familiar to the reader that are "perceived as part of a conceptual frame and ultimately integrated into the world the readers know' (Fludernik \& Häusler-Greenfield, 2009, p.55). Its narrative meaning is established though the relationship between a reader's response, the author's conscious and unconscious intentions, and the stylistic construction ${ }^{1}$ of the literary text itself. In this way, creative writing works to create a connection between its fictional world and the real world of the reader. As Miall and Kuiken (1999) conclude from a number of empirical studies: 'during literary reading, the perspectives that we have, perhaps unthinkingly, acquired from our culture are especially likely to be questioned.. This points to the adaptive value of literature in reshaping our perspectives..., especially by impelling us to reconsider our system of convictions and values' (p.127). This observation supports the notion of practice-based research as being consistent with more traditional scientific methodologies, as they 'bear intrinsic similarities in their attempts to illuminate aspects of the human condition...and work toward advancing human understanding' (Leavy, 2014, p.3).

Creative writing works

to create a connection

between its fictional world and the real world of the reader

\section{Conclusion}

Creative writing, and by extension all the unique specialisms and approaches of practice-led research, as a process of decontextualisation and recontextualisation, working in tandem with critical reflection and analysis, can produce original insights that may remain overlooked or undiscovered by more conventional research methodologies. In its impact beyond academia, potentially changing behaviours and attitudes in its readers and audiences as a result of defamiliarisation and re-writing through interpretation, creative writing can be seen as a valuable research methodology that, alongside more traditional research outputs, can bring new insights and original contributions to knowledge.

\section{References}

Ali, M. (2007) Brick Lane. London: Black Swan.

Barrett, E. (2010) Foucault's 'What is an Author': Towards a critical discourse of practice as research. In Practice as research: approaches to creative arts enquiry, edited by E. Barrett, E. \& B. Bolt. London, I.B. Tauris.

Booth, W.C. (1983) The Rhetoric of Fiction. London: University of Chicago Press.

Carter, P. (2010) Interest: The Ethics of Invention. In Practice as research: approaches to creative arts enquiry, edited by E. Barrett \& B. Bolt. London, I.B. Tauris.

Crewe, J. (2017) Another London: A novel and critical commentary investigating representations of the white working class in media, politics and literature in an age of multiculturalism, PhD dissertation. The University of Surrey. Currie, G. (2010) Narratives and narrators a philosophy of stories. Oxford: Oxford University Press.

Fludernik, M. \& Häusler-Greenfield, P. (2009) An Introduction to narratology. Abingdon; New York: Routledge.

Jameson, F. (2010) The political unconscious: narrative as a socially symbolic act. London: Routledge.

Kuiken, D Miall, D.S. \& Sikora, S. (2004) Forms of SelfImplication in Literary Reading. Poetics Today, 25(2): 171-203 Leavy, P. (2014) Method Meets Art, Second Edition: Arts-Based Research Practice. New York: Guilford Publications. Miall, D.S. \& Kuiken, D. (1999) What Is Literariness? Three Components of Literary Reading. Discourse processes, 28(2): 121

Phillips, C. (2004) A Distant Shore. London: Vintage. REF - Research Excellence Framework (2018) Draft guidance on submissions. Retrieved from https://www.ref. ac.uk/media/1016/draft-guidance-on-submissionsref-2018_1.pdf

Scholes, R., Phelan, J. \& Kellogg, R.L. (2006) The nature of narrative. Oxford: Oxford University Press.

Sklar, H. (2013) The art of sympathy in fiction forms of ethical and emotional persuasion. Amsterdam: John Benjamins Publishing Company.

Sullivan, G. (2009) Making Space: The purpose and place of practice-led research. In Practice-led research, research-led practice in the creative arts, edited by $\mathrm{H}$. Smith \& R.T. Dean. Edinburgh: Edinburgh University Press.

About the author

Dr Jonathon Crewe is a Senior Lecturer in Film Production in the London School of Film, Media and Design at the University of West London

Keywords

Creative writing, practice-led, narrative, fiction, focalisation

This is an open access article under the terms of the Creative Commons Attribution License (https://creativecommons.org/ licenses/by/4.0/), which permits use, distribution and reproduction in any medium, provided the original work is properly cited. (c) The Authors. New Vistas Published by University of West London.

The design, art direction and photography elements remain the intellectual property of the copyright holders and are not included in the Creative Commons Attribution license applied to the rest of this work. Photographs \& illustrations () Jebens Design Ltd (Jebens Design - www.jebensdesign.co.uk). Cover Photography (Claire Williams Photography - www.clairewilliamsphotography.co.uk). 